\title{
The coronary sinus reducer: a validate option for "no-option" labeled patients. Clinical evidences and new perspectives
}

\author{
Reductor del seno coronario: una opción de validación para pacientes \\ etiquetados de "no opción". Evidencias clínicas y nuevas perspectivas.
}

Michele Bellamoli', Carlo Zivelonghi², Federico Marin ${ }^{1}$, Flavio L. Ribichini', Stefan Verheye ${ }^{2}$, Pierfrancesco Agostoni ${ }^{2}$

\begin{abstract}
Refractory angina pectoris is a condition characterized by the presence of debilitating angina symptoms despite optimal medical therapy due to severe and/or diffuse coronary artery disease not amenable for revascularization either by percutaneous or surgical approach.

The coronary sinus Reducer is a percutaneous device designed to increase coronary sinus pressure to achieve a redistribution of the arterial coronary blood flow from the sub-epicardial layers towards the ischemic sub-endocardium in patients with refractory angina. The aim of this review is to provide a description of the Reducer, to report results from clinical studies available up to date and to discuss about future employment and perspectives.
\end{abstract}

\section{RESUMEN}

La angina de pecho refractaria es una condición caracterizada por la presencia de síntomas anginosos a pesar de la terapia médica óptima debido a enfermedad coronaria severa y/o difusa, que no es susceptible de revascularización tanto por vía percutánea como por cirugía de revascularización miocárdica.

El reductor del seno coronario es un dispositivo percutáneo diseñado para aumentar la presión venosa coronaria para lograr una redistribución del flujo sanguíneo coronario arterial desde capas subepicárdicas hacia el subendocardio isquémico en pacientes con angina de pecho refractaria. El objetivo de esta revisión es proporcionar una descripción del reductor del seno coronario, sobre los resultados de estudios clínicos disponibles hasta la fecha y discutir sobre su uso en el futuro y sus perspectivas.

Key words: angina refractaria, reductor del seno coronario.

Revista Argentina de Cardioangiología Intervencionista 2019;10(1):21-25. DOI: 10.30567/RACI/201901/0021-0025

\section{INTRODUCTION}

Refractory angina pectoris is a chronic disabling condition affecting a growing number of patients (10-15\%) with severe ischemic heart disease ${ }^{1}$. It can be defined as the presence of debilitating angina despite optimal medical therapy due to severe and/or diffuse coronary artery disease (CAD) not amenable for revascularization either by percutaneous or surgical approach. Life expectancy for these patients doesn't differ significantly from other patients with chronic ischemic heart disease $e^{2,3}$, but their quality of life is poorer, their incidence of re-hospitalization is higher ${ }^{4}$, and they frequently experience depression and anxiety because of their disease 5 . Moreover, patients with refractory angina should be managed with many anti-ischemic drugs and are relatively young (60-65 years) ${ }^{6}$.

This "no-option" labeled population represents a complex and heterogeneous group ${ }^{78}$. Most of them are not good candidates for revascularization due to several technical implications, such as the presence of complex coronary total occlusions, highly diffuse coronary artery disease, recurrent coronary restenosis after percutaneous coronary revascularization (PCI) or occluded bypass after coronary artery bypass graft surgery (CABG). Other patients continue complaining about disabling angina despite successful revascularization: this is called "residual" or "persistent" angina and is supposed to affect $25 \%$ of patients af-

1. Division of Cardiology, Department of Medicine, University of Verona, Italy

2. Department of Cardiology, ZNA Middelheim, Antwerpen, Belgium

$\triangle$ Correspondencia: Pierfrancesco Agostoni MD, PhD. Hartcentrum, Ziekenhuis Netwerk Antwerpen (ZNA) Middelheim. Antwerp, Belgium. Phone: +31650286115.agostonipf@gmail.com

Los autores declaran no tener conflictos de intereses

Recibido:04/02/2019||Aceptado:07/03/2019 ter one year and $45 \%$ after 3 years following revascularization?. Furthermore, another group of patients suffer from micro-vascular angina in the absence of significant epicardial coronary stenosis ${ }^{7}$.

This wide range of clinical entities may explain the difficulties in assessing the effectiveness of various proposed therapeutic alternatives $^{10-12}$. The impact of refractory angina in terms of healthcare costs indicates the need for expanding strategies for the treatment of these patients ${ }^{12}$ which has been currently limited mainly to traditional anti-anginal therapy and lifestyle changes in the past few years ${ }^{13,14}$. In fact, several novel anti-ischemic drugs such as ivabradine or ranolazine, and alternative therapies like transmyocardial laser revascularization, extracorporeal shockwave therapy, spinal cord stimulation, gene therapy or cell therapy brought only limited benefits in this population ${ }^{11,15}$

The coronary sinus reducer (CSR) is a novel percutaneous implantable device designed to narrow the coronary sinus (CS) in order to reduce angina burden in patients experiencing refractory angina; and received CE approval in November 2011. The concept of narrowing the coronary sinus comes from Beck's and others heart surgeons intervention $\mathrm{s}^{16,17}$, who started performing a surgical restriction of the main cardiac vein to obtain redistribution of myocardial blood flow into ischemic territories, with encouraging results. This promising technique was then almost forgotten due to the rapid development of surgical and percutaneous revascularization procedures, but recently the increasing number of patients with refractory angina called back this idea. Therefore, the CS Reducer has been developed and introduced in clinical practice as a new device for the treatment of these patients ${ }^{18,19}$.

\section{DEVICE AND IMPLANTATION PROCEDURE}

The CSR is a stainless steel mesh pre-mounted on an hourglass shaped balloon catheter, intended to be percutaneous- 


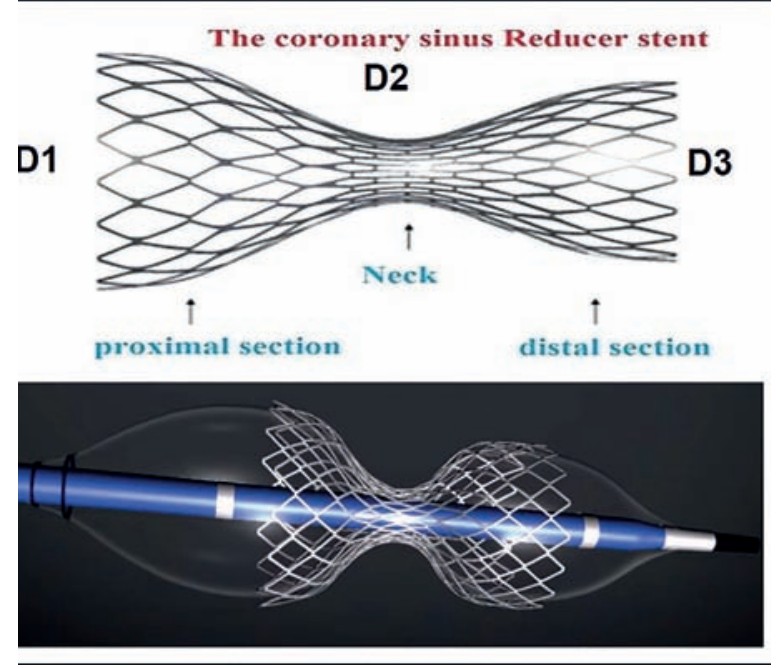

Figure 1. The Reducer device. Above: expanded device (note the three different diameters determining the hourglass shape). Below: expanded device mounted on the delivery balloon with their hourglass shape.

ly implanted to create a controlled narrowing into the CS, to finally increase coronary venous pressure (Figure 1).The device is provided in a single size suitable for CS diameters ranging from 9 to $14 \mathrm{~mm}$.

Through a percutaneous approach from the right-jugular vein, a 6 french $(\mathrm{Fr})$ diagnostic catheter (Multipurpose or Amplatz left) is advanced to measure right atrial pressure (RAP) and to selectively gain the CS, which is injected to assess the anatomy. RAP over $15 \mathrm{mmHg}$ represents a contraindication to the implantation, to avoid treating patients with uncontrolled heart failure.Then, the $6 \mathrm{Fr}$ diagnostic catheter is exchanged with a 9 Fr guiding catheter, which is positioned distally into the CS, allowing to advance the reducer up to the place chosen for the implant. The 9 Fr guiding catheter is then retracted and the reducer balloon is inflated by the help of contrast injection to guide correct implantation. After deflation and retrieval of the balloon, a final angiogram evaluates the positioning and excludes any complications such as perforations (Figure 2). After the procedure, a short period of dual antiplatelet therapy with aspirin and clopidogrel is recommended (usually one month).

\section{INSIGHT THE MECHANISM OF ACTION}

The potential benefit in reducing coronary sinus diameter in ischemic heart disease is based on the findings first described by Camici et al. ${ }^{7}$, later by Banai et al. ${ }^{18}$. In a normal heart, during exercise, the sympathetic-mediated vasoconstriction of the sub-epicardial vessels leads to an increase of blood flow to the sub-endocardial layers ${ }^{20}$ : in patients with obstructive CAD this mechanism is dysfunctional ${ }^{21}$. In addition, in ischemic heart disease, the high left ventricular end-diastolic pressure worsen the sub-endocardial ischemia increasing coronary flow resistance. A controlled narrowing of the CS in ischemic myocardium raises the pressure in the venous drainage system, inducing arterial capillaries dilatation and reducing flow resistances, leading to a redistribution of blood from the less ischemic sub-epicardium to the more ischemic sub-endocardium ${ }^{22,23}$. This beneficial effect was first observed pre-clinical experiments in animals $s^{24-27}$. The effect of the reducer starts once the endothelialization of the device has completed, so it takes a few months after implantation ${ }^{18,22}$.
Another potential mechanism of action is linked to the possible angiogenic effect of the device ${ }^{28}$. This theory is still debated, and comes from histological findings of myocardial neo-angiogenesis after the introduction of a small balloon pump into the CS designed to reduce acute ischemic injury after myocardial infarction in the early nineties ${ }^{27}$.

\section{PATIENT SELECTION AND CONTRAINDICATIONS}

The best candidate for reducer implantation is a patient with all these features: 1) stable angina with Canadian Cardiovascular Society (CCS) class II-IV; 2) objective evidence of myocardial ischemia in the left coronary artery distribution; 3) optimized antianginal medical therapy; 4) no further options for coronary surgical or percutaneous revascularization ${ }^{29}$

Not good candidates are patients with no objective evidence of myocardial ischemia or limited ischemia on the right coronary artery (RCA) territory: the venous drainage from the RCA is usually ensured by the middle cardiac vein (MCV), inserting next to the CS ostium, distally from the Reducer implantation site. However, an atypical implantation of the Reducer in the MCV in a patient with RCA related-ischemia has recently been reported without peri-procedural complications (30), suggesting the possibility of an off-label procedure in such patients when CS anatomy is unfavorable and MCV is of suitable size. Reducer is furthermore not advisable in cases of heart failure with severe systolic impairment (ejection fraction $<30 \%$ ) which could benefit from cardiac resynchronization therapy, in patients with mean $\mathrm{RAP}>15 \mathrm{mmHg}$ or in recent (<3 months) $\mathrm{PCI}$ or $\mathrm{CABG}^{29}$.

\section{THE NON-RESPONDERS: NEW EVIDENCES}

CSR implantation results in an improvement in symptoms in about $70-80 \%$ of patients ${ }^{29}$; the reason why the remaining percentage does not benefit is still matter of debate. Factors such as angina related to ischemia on the right coronary territory, coexisting heart failure related symptoms or non-angina chest pain are proposed ${ }^{29}$.

However, the most physiological supported hypothesis to date is that an inadequate pressure gradient across the Reducer could significantly influence the device's efficacy. This is more likely to happen in patients with a well-developed alternative coronary venous drainage system, as recently suggested by San Raffaele's interventionalists ${ }^{31}$. Therefore, measuring the difference between right atrial pressure (corresponding to CS pressure) at the baseline and the CS systolic wedge pressure after reducer implantation could help detecting non-responders: such patients might have scarce CS pressure increment as compared to responders. Excluding coronary artery disease progression at follow-up or malposition/thrombosis of the device by CT scan is otherwise important in case of non-responding ${ }^{31}$.

\section{PROCEDURAL COMPLICATIONS}

CSR implantation has shown to be a safe procedure with a very low rate of peri-operative complication ${ }^{29}$; however several troubles as CS dissection during catheter or wire manipulation, direct or late device migration, pericardial tamponade due to CS rupture may theoretically occur. In the CO- 


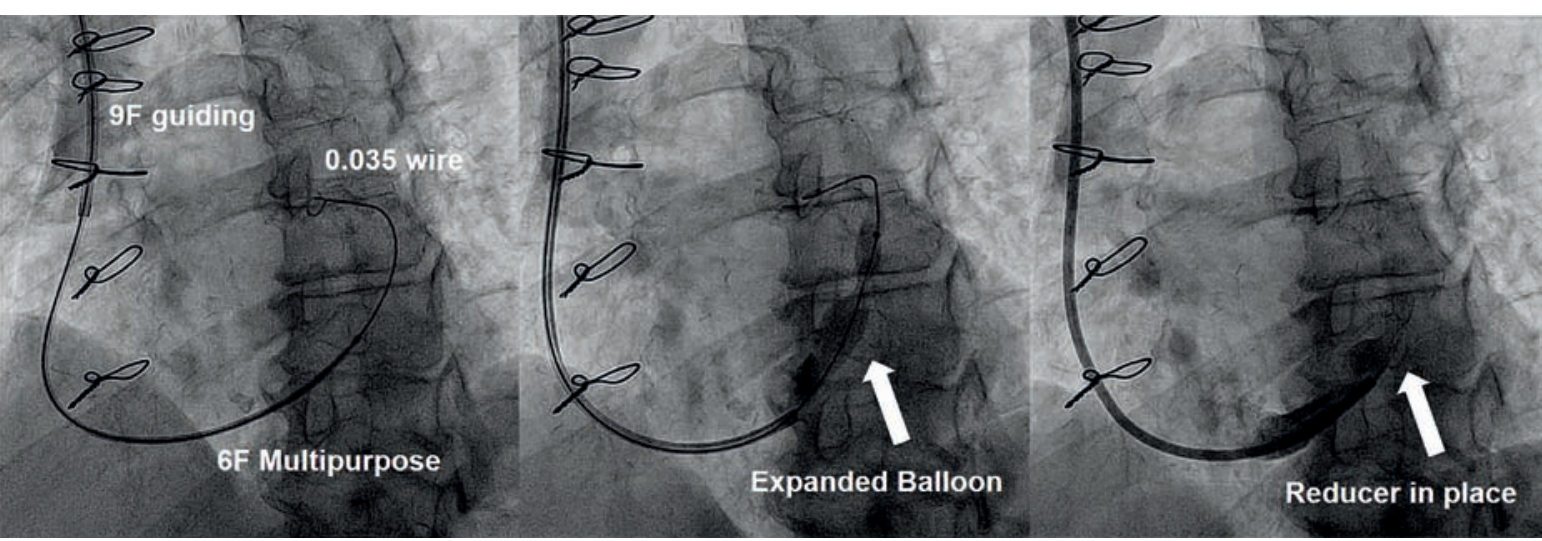

Figure 2. Angiographic image of the coronary sinus (A) Deployment of the Reducer in the coronary sinus (B) Final angiographic control after Reducer implantation (C)

SIRA trial ${ }^{22}$ only one case of peri-procedural myocardial infarction was registered in the treatment group, with no evidence of device migration or occlusion at CT angiography. The first systematically described managed case of CS perforation was recently reported by Bernardo Cortese et al..$^{32}$ : after implantation of the device and balloon retrieval, they noticed free extravasation of contrast in the left atrium due to CS rupture. No hemodynamic impairment occurred: the patient was successfully treated with protamine sulfate administration and a semi-compliant balloon inflation for 5 minutes was performed. No pericardial effusion was detected at echo and the patient was discharged two days later. Thus, in this case, a potential life-threatening complication was successfully managed without serious implications.

\section{EFFICACY PERFORMANCES IN CLINICAL STUDIES}

The feasibility, safety and efficacy of the reducer implantation were first evaluated in pre-clinical experiments in swine models, showing a reduction in extent and severity of myocardial ischemia ${ }^{29,33}$. Then, further studies in men assessed the role of the device in improving quality of life and parameters of ischemia in patients with refractory angina.

The first-in-man study was a multicenter, non-randomized prospective study ${ }^{18}$ involving 15 patients with refractory angina treated with the Reducer at 3 medical centers. All procedures were completed with no adverse events. Most of the patients $(85 \%)$ reported a reduction in CCS angina class; clinical improvement started a few weeks after the procedure. The extent and severity of myocardial ischemia assessed by dobutamine echocardiography and by thallium SPECT studies were significantly reduced in 8 out of 13 patients and 4 out of 10 patients respectively at 6 months follow-up ${ }^{18}$.

Data about 21 patients treated with the reducer in two centers (Antwerp Cardiovascular Center, Belgium, and Tel Aviv Medical Center, Israel) were published in Eurointervention in $2014^{34}$. Patients with refractory angina not susceptible for surgical or percutaneous coronary revascularization, with objective evidence of myocardial ischemia and ejection fraction $\geq 25 \%$ were included. The implant of the reducer was associated with a significant improvement in angina class in $85 \%$ of the cases; medium CCS class values decreased significantly at six months follow-up from an average of $3.3 \pm 0.6$ to $2.0 \pm 1.0$. Clinical improvement started a few weeks after the procedure and was maintained at fo- llow-up. In addition, wall motion severity index (WMSI) at stress assessed by dobutamine echocardiography at 6 months follow-up improved significantly; summed stress score (SSS) and summed difference score (SDS) at thallium stress scans were significantly reduced, demonstrating an improvement in the extent and severity of the ischemic segments after CSR implantation ${ }^{34}$

To date, the only randomized sham-controlled trial evaluating the efficacy of CS reducer as a treatment for refractory angina is the COSIRA trial (COronary SInus Reducer for treatment of refractory Angina) $)^{22}$. The study involved 11 clinical centers; a total of 104 patients were randomized. Participants were randomly assigned in a 1:1 ratio to undergo either implantation of the Reducer (treatment group, $52 \mathrm{pa}$ tients) or the sham procedure (control group, 52 patients). The study was double-blinded: neither the patients nor cardiologists evaluating the clinical status at baseline and follow-up were aware of the treatment arm. The primary endpoint of the study was the reduction in angina symptoms evaluated by CCS score: 18 out of 52 patients (35\%) in the treatment group versus 8 out of $52(15 \%)$ in the control group had an improvement of at least two CCS classes. This improvement was significant $(p=0.02)^{22}$. An improvement of at least one CCS class was registered in $71 \%$ of patients in the treatment group (37 of 52 patients) compared to $42 \%$ (22 of 52$)$ in the control group ( $p=0.003)$. In addition, quality of life assessed with the Seattle Angina Questionnaire (SAQ) was significantly improved in the Reducer group as compared to the control group. No significant between-groups differences were found in improvement in exercise time during ergometry or in the extent of ischemia evaluated by stress echocardiography or myocardial scintigraphy at 6 months follow-up ${ }^{22}$.

Data from a retrospective registry in Utrecht about $23 \mathrm{pa}-$ tients treated with the Reducer were published in 2016 by Abawi et al. ${ }^{35}$ Patients with refractory angina despite optimal medical therapy (CCS class 2-4) with CAD not suitable for revascularization and documented inducible myocardial ischemia underwent Reducer implantation. Unlike the COSIRA ${ }^{22}$, which included only patients with a positive dobutamine stress echocardiography at the baseline, in this registry all forms of proven inducible ischemia were admitted. In line with previous studies ${ }^{18,22,34}$ the CSR implantation in these patients was proven to be safe with no procedural-related complications. The efficacy endpoint (any reduction in CCS class and revascularization free survival) was reached 
in most of the patients $(74 \%, 17$ patients) few weeks after the procedure $^{35}$.

Recently, new data from real-world experiences with Reducer implantation have been published. Giannini and others from San Raffaele Scientific Institute in Milan reported their results coming from 50 consecutive patients treated with Reducer between March 2016 and August 2018. ${ }^{36}$ They demonstrated an improvement of at least one CCS angina class in $80 \%$ of patients and of two CCS angina class in $40 \%$ of patients at 4 months follow-up, with a preserved result at 1 year. They also reported an improvement in quality of life assessed by Seattle Angina Questionnaire (SAQ) and 6-min walking test distance, without any device-related adverse event during the procedure or at follow-up. Reducing in antianginal drugs was possible for $19 \%$ of the patients at follow-up. No data regarding reduction in objective myocardial ischemia assessed by imaging techniques were reported. Results from another single-center experience in Tel-Aviv were published by Konigstein and others in Eurointervention on July $2018^{37} .48$ patients underwent reducer implantation and then were evaluated at 6 months and 1-year follow-up. No peri-procedural or long-term adverse events were recorded. The main findings of the study can be summarized in 3 points. First, reducer implantation was associated with significant reduction of angina severity and improvement in quality of life, as reflected by the SAQ. Second, exercise duration evaluated by Treadmill exercise test and 6 minute-walking test distance increased. Third, but not less important, ejection fraction at stress increased and wall motion severity index (WMSI) improved significantly when evaluated by means of dobutamine echocardiography at six-months follow-up ${ }^{37}$.

In the multi-center "reduce" clinical registry ${ }^{38}$ data from one hundred forty one consecutive patients who underwent reducer implantation at 3 high volume medical centers (San Raffaele Hospital in Milan, Tel-Aviv medical center and Antwerp Cardiovascular center) were collected and analyzed. Patients with obstructive CAD with no-option for further revascularization, suffering from chronic disabling angina (CCS class 2-4) and with pre-implant objective demonstration of myocardial ischemia by physical or pharmacological stress tests were treated with Reducer. No peri-procedural or long-term complications occurred; mean CCS class and all SAQ items improved significantly; the number of anti-ischemic drugs prescribed was significantly reduced during a median follow-up of 14 months. The choice to perform a further ischemia testing during follow-up was left to treating physician, thus data regarding objective ischemia reduction after Reducer implantation were not complete and consistent. However authors reported a significant reduction in ischemia extent assessed by myocardial scintigraphy (available in 37 patients) and a significant reduction in inducible ischemia evaluated by dobutamine stress echocardiography (available in 42 patients) ${ }^{38}$.

To date, data regarding the improvement in objective parameters of ischemia following Reducer implantation are sti11 limited to restricted non-randomized cohorts. In the last few years cardiac magnetic resonance became the gold standard imaging technique to evaluate myocardial viability and its use will spread more and more to assess myocardial per- fusion and ischemia. What we need now is to evaluate the role of dipyridamole stress cardiac magnetic resonance with myocardial perfusion reserve index (MPRI) calculation to objectively measure the effect of Reducer implantation. Available data in this setting come from Giannini's experience in Milan in patients with refractory angina without obstructive coronary artery disease treated with reducer ${ }^{39}$. Eight patients underwent CS Reducer implantation for the treatment of microvascular angina: all 3 patients that underwent dipyridamole CMR with MPRI calculation in this group were found to have an increasing MPRI of the ischemic segments and an increasing mean MPRI of the whole ventricle after intervention. CMR with MPRI was also employed by Konigstein and others in 15 patients undergoing CS Reducer implantation with a demonstration of an increasing global MPRI from baseline to 4 months follow-up $(1.46 \pm 0.40 \text { to } 1.80 \pm 0.78)^{29}$. Larger studies with longer follow-up are now required in this setting to objectively assess the reduction in ischemia burden with this accurate technique in patients treated with reducer.

Further ongoing studies will evaluate the impact of CSR on refractory angina in larger number of patients. A multi-center observational clinical study (Reducer-I - NCT02710435) will include 400 patients from 40 centers in Europe with a 5 years extended follow-up; a phase III multi-center, randomized, double blinded, sham-controlled clinical trial will enroll 380 patients from more than 30 centers across North America (COSIRA II).

\section{FUTURE PERSPECTIVES}

The prevalence of refractory angina is still increasing in relation to the increase in survival of patients with ischemic heart disease and the aging of the population. CS Reducer should be always considered in this setting, where appropriate indications exist, because of the safety of its implant, the proven efficacy in reducing anginal symptoms and in improving the quality of life of these patients ${ }^{22}$.

The use of CS Reducer is now diffusing in Europe due to previously cited promising clinical findings and experiences, but remains still under adopted. Future perspectives and broadening of its indications will be matter of upcoming literature. Reducer implantation in patients suffering from microvascular angina without obstructive CAD as already be tested in small series ${ }^{39}$, enlightening promising results. What should be attempted now is to go beyond the purpose for which Reducer is currently approved: hence to demonstrate a possible role of this device in ter$\mathrm{ms}$ of increased survival in patients with highly diffuse coronary artery disease not eligible for revascularization regardless of symptoms, as recently proposed by Lozano et al.(40). The mortality rate in this group still remains very high, and positive results in decreasing the ischemia burden after Reducer implantation ${ }^{29,37,39}$ may be a solid start point to test in a clinical study the employment of CS Reducer in this population. However, evaluating the impact on myocardial ischemia with advanced techniques such as stress cardiac magnetic resonance in larger groups of patients treated with Reducer will be the first step to start exploring this new exciting perspective ${ }^{41}$. 


\section{BIBLIOGRAFÍA}

1. McGillion M, Arthur HM, Cook A, Carroll SL, Victor JC, L'Allier P L, et al. Management of patients with refractory angina: Canadian Cardiovascular Society/Canadian Pain Society joint guidelines. The Canadian journal of cardiology. 2012;28(2 Suppl):S20-41.

2. Weintraub WS, Spertus JA, Kolm P, Maron DJ, Zhang Z, Jurkovitz C, et al. Effect of PCl on Quality of Life in Patients with Stable Coronary Disease. N Eng Med. 2008;359:677-87.

3. Henry TD, Satran D, Hodges JS, Johnson RK, Poulose AK, Campbell AR, et al. Long-term survival in patientswith refractory angina. Eur Heart J. 2013:34:2683-8.

4. Povsic TJ, BroderickS, Anstrom KJ, Shaw LK, Ohman EM, Eisenstein EL, et al. Predictors of long-term clinical endpoints in patients with refractory angina. Journal of the American Heart Association. 2015;4():1-12.

5. Andrell P, Ekre O, Grip L, Wahrborg P, Albertsson P, Eliasson T, et al. Fatality, morbidity and quality of life in patients with refractory angina pectoris. Int J Cardiol. 2011;147(3):377-82.

6. Brorsson B, Bernstein SJ, Brook RH, Werkö L. Quality of life of patients with chronic stable angina before and four years after coronary revascularisation compared with a normal population. Heart. 2002;87:140-5.

7. Camici PG, Filippo C. Coronary Microvascular Dysfunction. N Eng J Med. 2007:356:830-40.

8. Mannheimer C, Camici P, Chester MR, Collins A, DeJongste M, Eliasson T, et al. The problem of chronic refractory angina; report from the ESC Joint Study Group on the Treatment of Refractory Angina. European heart journal. 2002;23(5):355-70.

9. Serruys PW. Assessing percutaneous intervention: re-appraising the significance of residual angina. Eurolntervention. 2015;10(11):1253.

10. Jolicoeur EM, Ohman EM, Temple R, Stockbridge N, Smith S, Mark D, et al. Clinical and research issues regarding chronic advanced coronary artery disease part II: Trial design, outcomes, and regulatory issues. American heart journal. 2008;155(3):435-44.

11. McNab D, Khan SN, Sharples LD. An open label, single-centre, randomized trial of spinal cord stimulation vs. percutaneous myocardial laser revascularization in patients with refractory angina pectoris: the SPiRiT trial. European heart journal. 2006;27:1048-53.

12. Henry TD, Satran D, Jolicoeur EM. Treatment of refractory angina in patients not suitable for revascularization. Nat Rev Cardiol. 2014;11(2):78-95.

13. Fihn SD, Gardin JM, Abrams J, Berra K, Blankenship JC, Dallas AP, et al. 2012 ACCF/AHA/ACP/AATS/PCNA/SCAI/STS Guideline for the diagnosis and management of patients with stable ischemic heart disease: a report of the American College of Cardiology Foundation/American Heart Association Task Force on Practice Guidelines, and the American College of Physicians, American Association for Thoracic Surgery, Preventive Cardiovascular Nurses Association, Society for Cardiovascular Angiography and Interventions, and Society of Thoracic Surgeons. J Am Coll Cardiol. 2012;60(24):e44-e164.

14. Kones R. Recent advances in the management of chronic stable angina II. Anti-ischemic therapy, options for refractory angina, risk factor reduction, and revascularization. Vasc Health Risk Manag. 2010;6:749-74.

15. Leon MB, Kornowski R, Downey WE, Weisz G, Baim DS, Bonow RO, et al. A blinded, randomized, placebo-controlled trial of percutaneous laser myocardial revascularization to improve angina symptoms in patients with severe coronary disease. J Am Coll Cardiol. 2005;46(10):1812-9.

16. BeckCS, Leighninger DS. Operations for coronary artery disease. J Am Med Assoc. 1954;156(13):1226-33.

17. Weigel G, Kajgana I, Bergmeister H, RiedI G, Glogar HD, Gyongyosi M, et al. Beck and back: a paradigm change in coronary sinus interventions--pulsatile stretch on intact coronary venous endothelium. J Thorac Cardiovasc Surg. 2007;133(6):1581-7.

18. Banai S, Ben Muvhar S, Parikh KH, Medina A, Sievert H, Seth A, et al. Coronary sinus reducer stent for the treatment of chronic refractory angina pectoris: a prospective, open-label, multicenter, safety feasibility first-inman study. J Am Coll Cardiol. 2007:49(17):1783-9.

19. Jolicœur EM, Banai S, Henry TD, Schwartz M, Doucet S, White CJ, et al. A phasell, sham-controlled, double-blinded studytesting the safety and efficacy of the coronary sinus reducer in patients with refractory angina: study protocol for a randomized controlled trial. Trials. 2013;14:46.

20. Feigl EO. The paradox of adrenergic coronary vasoconstriction Circulation. 1987;76:737-45
21. CreaF,Galassi AR, KaskiJC, Pupita G, TamimiH, Davies GJ. Effect of Theophylline on Exercise-Induced Myocardial Ischemia. Lancet. 1989:683-86.

22. Verheye S, Jolicoeur EM, Behan MW, Pettersson T, Sainsbury P, Hill J, et al. Efficacy of a device to narrow the coronary sinus in refractory angina. The New England journal of medicine. 2015;372(6):519-27.

23. Sato M, Saito T, Mitsugi M, Saitoh S, Niitsuma T, Maehara K, et al. Effects of cardiac contraction and coronary sinus pressure elevation on collateral circulation. Am J Physiol. 1996;271(4 Pt 2):H1433-40.

24. Ido A, Hasebe N, Matsuhashi H. Coronary sinus occlusion enhances coronary collateral flow and reduces subendocardial ischemia. Am J Physiol Heart Circ Physio. 2001;280:1361-7.

25. Gross L, Blum L, Silverman G. ExperimentalAttempts To Increase The Blood Supply To The Dog's Heart By Means Of Coronary Sinus Occlusion. J Exp Med. 1937;65(1):91-108

26. Rouleau JR, White M. Effects of coronary sinus pressure elevation on coronary blood flow distribution in dogs with normal preload. Can J Physiol Pharmacol. 1985;63(7):787-97.

27. Mohl W, Glogar DH, Mayr H. Reduction of infarct size induced by pressure-controlled intermittent coronary sinus occlusion. Am J Cardiol 1984:53:923-8.

28. Paz Y, Shinfeld A. Re: "Transcatheter treatment for refractory angina with the coronary sinus Reducer" by Maayan Konigstein et al. Eurolntervention. 2015;11(6):727-8

29. Konigstein M, Giannini F, Banai S. The Reducer device in patients with angina pectoris: mechanisms, indications, and perspectives. Eur Heart $J$ 2018;39(11):925-33

30. Gorla R, Giannini F, Bedogni F, De Marco F. Unusual Implantation of a Coronary Sinus Reducer in the Middle Cardiac Vein. J Invasive Cardiol. 2018;30(8):E69-E70

31. Baldetti L, Colombo A, Banai S, Latib A, Esposito A, Palmisano A, et al. Coronary sinus Reducer non-responders: insights and perspectives. Eurolntervention. 2018;13(14):1667-9.

32. Cortese $B$, di Palma G, Latini R. Coronary sinus perforation during reducer implantation. Catheter Cardiovasc Interv. 2018;91(7):1291-3.

33. Banai S, Ben-Muvhar S, Tsehori J, Keren G, Paz Y, Reisner S, et al. Transcatheter coronary sinus narrowing with the Neovasc Reducer-an alternative treatmentapproach for patients with disabling angina who arenotcandidates for revascularization procedures - a preclinical study. . Abstract presentation at the 2004 annual conference of the Israel Heart Society. 2004.

34. Konigstein M, Meyten N, Verheye S, Schwartz M, Banai S. Transcatheter treatment for refractory angina with the Coronary Sinus Reducer. Eurolntervention: journal of EuroPCR in collaboration with the Working Group on Interventional Cardiology of the European Society of Cardiology. 2014;9(10):1158-64

35. Abawi M, Nijhoff F, Stella PR, Voskuil M, Benedetto D, Doevendans PA, et al. Safety and efficacy of a device to narrow the coronary sinus for the treatment of refractory angina: A single-centre real-world experience. Neth Heart J. 2016.

36. Giannini F, Baldetti L, Ponticelli F, Ruparelia N, Mitomo S, Latib A, et al. Coronary Sinus Reducer Implantation for the Treatment of Chronic Refractory Angina: A Single-Center Experience. JACC Cardiovasc Interv. 2018;11(8):784-92.

37. Konigstein M, Bazan S, Revivo M, Banai S. Coronary Sinus Reducer implantation improves symptoms, ischaemia and physical capacity in patients with refractory angina unsuitable for myocardial revascularisation: a single-centre experience. Eurolntervention. 2018;14(4):e452-e8.

38. Giannini F, Baldetti L, Konigstein M, Rosseel L, Ruparelia N, Gallone G, et al. Safety and efficacy of the reducer: A multi-center clinical registry-REDUCE study. International journal of cardiology. 2018;269:40-4

39. Giannini F, Baldetti L, lelasi A, Ruparelia N, Ponticelli F, Latib A, et al. First Experience With the Coronary Sinus Reducer System for the Management of Refractory Angina in Patients Without Obstructive Coronary Artery Disease. JACC Cardiovasc Interv. 2017:10(18):1901-3.

40. Lozano I, Capin E, Lee Hwang DH, Lopez-Palop R, Segovia E. Coronary Sinus Reducer Implantation:Potential New Horizons Where it Should BeTested. JACC Cardiovasc Interv. 2018;11(16):1658.

41. Giannini F, Baldetti L, Ruparelia N, Ponticelli F, Colombo A. Reply: Coronary Sinus Reducer Implantation: Potential New Horizons Where it Should Be Tested. JACC Cardiovasc Interv. 2018;11(16):1658-9. 